\title{
A Study on Learning Engagement of Higher Vocational College Students
}

\author{
Xiao Li \\ Suzhou Industrial Park Institute of Services Outsourcing, \\ Ruoshui Road ,Suzhou Industrial Park, Jiangsu, China \\ 113538941@qq.com
}

Keywords: Higher vocational college students; Learning engagement; Survey.

\begin{abstract}
This study took 599 higher vocational college students as subjects, using UWES-S to examine the current situation of higher vocational students' learning engagement. The results showed that: Male students' learning engagement is significantly higher than that of female students; the learning engagement of Polytechnic and art students is significantly higher than that of liberal arts students; junior students' learning engagement is significantly higher than that of freshman and sophomore students, while the sophomores' learning engagement is significantly higher than that of freshmen.
\end{abstract}

\section{Introduction}

Learning engagement is a positive emotional and mental state. It is the individual's abundant energy, good psychological characteristics and immersive learning state in learning, namely, vitality, dedication, and concentration [1]. The engagement can enable students to produce optimistic and positive emotional experiences, unwilling to give up and continue to try in the face of difficulties, including behaviors such as participation, effort, concentration, and attention. Scholars at home and abroad tend to enrich and improve the research on the meaning of learning engagement, indicating that the perspective of international higher education shifts the evaluation of education from a result-oriented paradigm to a process-oriented paradigm. Paying attention to the student's learning process.

At present, there are more and more researches on learning engagement in China. However, the researches on the higher vocational college students are rare. Now we study the vocational colleges, understanding the students 'current situation in learning engagement, and make constructive suggestions for raising learning engagement.

\section{Research Methods}

\section{1 subjects}

This study uses an overall sampling method, questionnaire investigation on three higher vocational College Students in Suzhou. 650 questionnaires were sent out and 599 valid questionnaires were returned, with an effective rate of $92.15 \%$. There are 201 boys and 398 girls; 187 freshmen, 225 sophomores, 187 juniors; 364 liberal arts students, 142 Polytechnic students and 93 art students.

\subsection{Questionnaire}

We use the Utrecht Work Engagement Scale-student(UWES-S) that revised by Li Xiying in 2010.this scale divides learning engagement into three dimensions of motivation, focus, and dedication, a total of 17 projects. The 7-point scoring method is used, from 1 to 7 respectively: never, almost none, rarely, sometimes, often, very often, always, and the higher the score, the higher the level of learning engagement.

Cronbach a coefficient of total scale is 0.919 , Motivation Subscale is 0.857, focus Subscale is 0.815 , dedication Subscale is 0.826 , The construct validity of the scale is very good [2] . 


\subsection{Statistical Methods}

We analyze data through t-test and analysis of variance use SPSS19.0.

\section{Results}

Gender, discipline and grade were taken as independent variables and learning engagement as dependent variables. The results show that: There is a significant difference in gender of higher vocational students' learning engagement, The learning engagement level of male students is significantly higher than that of female students; There is a significant difference in discipline of higher vocational students, and the liberal arts students are significantly lower than those of Polytechnic and art students; There are also significant differences in the learning engagement of higher vocational students in grades, among which junior students are significantly higher than other students in learning engagement. And sophomore students in learning engagement are significantly higher than freshman students. Seeing table 1 to 3 for details

Table 1 Analysis on gender difference of higher vocational college students' learning engagement

\begin{tabular}{ccccc} 
& \multicolumn{5}{c}{$(\mathrm{N}=599)$} & $\mathrm{p}$ \\
\hline $\begin{array}{c}\text { Male } \\
(\mathrm{M} \pm \mathrm{SD})\end{array}$ & $\begin{array}{c}\text { Female } \\
(\mathrm{M} \pm \mathrm{SD})\end{array}$ & $\mathrm{t}$ & $<.001$ \\
\hline $\begin{array}{c}\text { Learning } \\
\text { engagement }\end{array}$ & $4.77 \pm 1.25$ & $4.24 \pm 1.10$ & 5.144 & \\
\hline
\end{tabular}

Table 2 Analysis on discipline difference of higher vocational college students' learning engagement ( $\mathrm{N}=599$ )

\begin{tabular}{cccccc}
\hline & $\begin{array}{c}\text { liberal arts } \\
(\mathrm{M} \pm \mathrm{SD})\end{array}$ & $\begin{array}{c}\text { Polytechnic } \\
(\mathrm{M} \pm \mathrm{SD})\end{array}$ & art & $\mathrm{F}$ & $\mathrm{p}$ \\
\hline $\begin{array}{c}\text { Learning } \\
\text { engagement }\end{array}$ & $4.20 \pm 1.12$ & $4.76 \pm 1.26$ & $4.76 \pm 1.09$ & 17.163 & $<.001$ \\
\hline
\end{tabular}

Table 3 Analysis on grade difference of higher vocational college students' learning engagement

\begin{tabular}{ccclcc}
\multicolumn{7}{c}{$(\mathrm{N}=599)$} \\
& $\begin{array}{c}\text { Freshmen } \\
(\mathrm{M} \pm \mathrm{SD})\end{array}$ & $\begin{array}{c}\text { Sophomore } \\
(\mathrm{M} \pm \mathrm{SD})\end{array}$ & junor & $\mathrm{F}$ & $\mathrm{p}$ \\
\hline $\begin{array}{c}\text { Learning } \\
\text { engagement }\end{array}$ & $4.10 \pm 1.09$ & $4.12 \pm 1.11$ & $4.76 \pm 1.09$ & 17.163 & $<.001$ \\
\hline
\end{tabular}

\section{Discussion}

\subsection{Comparison of gender differences in learning engagement}

The engagement level of male students is significantly higher than that of female students, This 
result is consistent with the research of Cui Wenqin[3].Because of traditional ideas and social evaluation, male students have always been more socially competent than female students, therefore, male students have a sense of superiority, which makes them more engaged in study than female students. This is inconsistent with the conclusions of Liao Youguo, Zhang Xinyong[4][5], They explained that, compared with male college students, female students devote more time to study, more often use learning strategies to complete learning tasks, and more often adopt positive ways to deal with failure 。In addition, female students may encounter prejudice and stereotypes in the future, so asked themselves fully devoted to learning, improve their professional skills, in order to enhance their competitiveness in the process of applying for a job in the future .Male students in higher vocational colleges have higher learning engagement than that of female students, which may be because higher vocational colleges emphasize more on cultivating students' practical ability and comprehensive application ability of knowledge [6].

\subsection{Analysis on the difference of learning investment in disciplines}

The liberal arts students are significantly lower than those of Polytechnic and art students in learning engagement. This is consistent with the conclusions of some researchers [7], The reason may be that it takes a long time for Polytechnic and art students to do experiments, curriculum design, data analysis and graphic design.

Cui Wenqin's research found that there was no significant difference in the level of learning engagement among college students of different disciplines [3].The inconsistency of the research results indicates that more empirical studies on the differences of college students' learning engagement need to be further verified on the basis of consistent measurement tools.

\subsection{The difference analysis of learning engagement in grade}

The higher learning engagement of junior students than freshmen and sophomores, The reason may be that freshmen are just coming out of high middle school's heavy schoolwork load, And has not yet adapted to the college environment and learning methods, Relax their demands on themselves 。 And even worse ,especially male college students, addicted to various online games cannot extricate themselves 。 But once they get into their sophomore year, With the increase of learning pressure, They have to put more effort and enthusiasm into their study. In junior year, As future career paths become clearer, In order to increase employment capacity, The engagement level of junior students will be improved.

\section{Conclusion}

Based on the analysis of 599 higher vocational college students' learning engagement, We found the results as follows:Male students' learning engagement level is significantly higher than that of female students; Polytechnic and art students' learning engagement is significantly higher than that of liberal arts students; junior students' learning engagement is significantly higher than that of freshman and sophomore students, while the sophomores' learning engagement is significantly higher than that of freshmen.

\section{References}

[1] Schaufeli, W.B, Salanova, M, Gonzalez-Roma, V \& Bakker, A. B. The measurement of engagement and burnout: A two sample confirmatory factor analytic approach[J]. Journal of Happiness Studies, 2002 3(1)71-92.

[2] Li Xiying,Huang Rong. Revised report of the university student learning engagement scale (uwes-s) [J]. Psychological Research, 20103 (1)84-88.

[3] Cui Wenqin. Study on the present situation and countermeasures of contemporary college 
students' learning engagement [J]. Exploration of Higher Education, 2012(6)67-71.

[4] Liao Youguo. College Students 'Academic Self-efficacy Effects on their Learning Value and Engagement [J].Journal of Ningbo University(Education Science Edition),2011 33(5)50-54.

[5] Zhang Xinyong,et al. A Study on the Learning Engagement and Health-related Hardiness of Undergraduates and Their Relationship[J].Psychological Research,2008(6)72-76.

[6] Wang Yashuang,Wang Xia. The Empirical Research on the Student Engagement and Its Influential Factors in Higher Vocational Colleges [J].Educational Research,2017(1)77-84.

[7] $\mathrm{Xu}$ Youyun. The learning burnout of college students and its relationship with coping style[J].China Journal of Health Psychology,2007(3)243-245. 